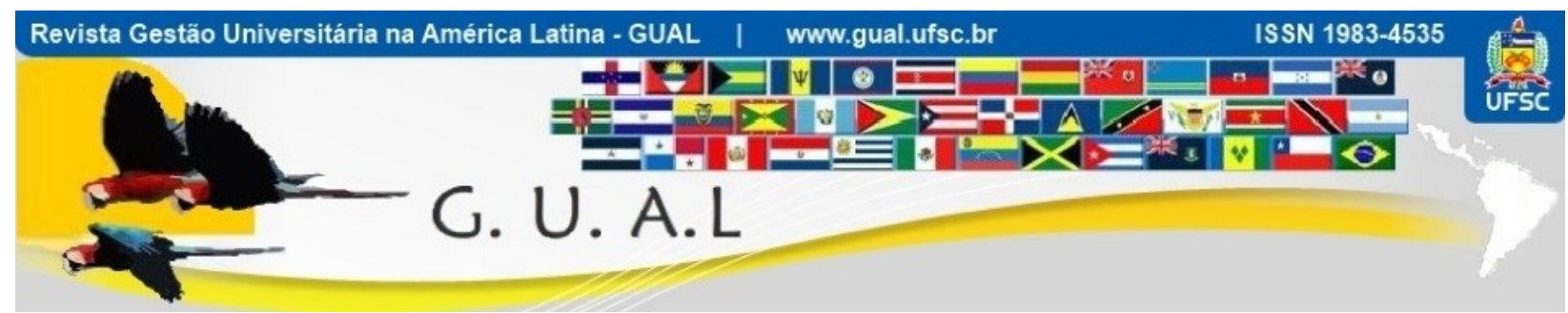

DOI: http://dx.doi.org/10.5007/1983-4535.2017v10n1p190

\title{
ESTRATÉGIAS EM UNIVERSIDADES: UMA ANÁLISE COMPARATIVA SOB A PERSPECTIVA INSTITUCIONAL
}

\section{STRATEGIES IN UNIVERSITIES: A COMPARATIVE ANALYSIS THROUGH THE INSTITUTIONAL PERSPECTIVE}

Juliana Marangoni Amarante, Doutoranda

Universidade Estadual de Maringá - UEM juliana.marangoni.amarante@gmail.com

João Marcelo Crubellate, Doutor Universidade Estadual de Maringá - UEM jmcrubellate@gmail.com

Victor Meyer Junior, Doutor Pontifícia Universidade Católica do Paraná - PUCPR e DePaul University victormeyerjr@gmail.com

Recebido em 25/maio/2015

Aprovado em 24/outubro/2016

Sistema de Avaliação: Double Blind Review

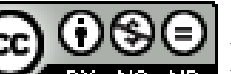

Esta obra está sob uma Licença Creative Commons Atribuição-Uso. 


\title{
RESUMO
}

Tendo a complexidade organizacional como pano de fundo, conjuntamente com a tipologia de Oliver (1991) que estabelece cinco padrões de respostas estratégicas distintas, por parte das organizações a processos institucionais, o presente estudo objetivou compreender como estratégias realizadas pela Universidade Estadual de Maringá (UEM) e pela Pontifícia Universidade Católica do Paraná (PUCPR) foram influenciadas por mudanças ocorridas em seus ambientes institucionais de referência no período compreendido entre os anos de 1996 e 2011. A pesquisa conduzida foi qualitativa e descritiva e utilizou a estratégia de estudo comparativo de casos, com recorte transversal e perspectiva longitudinal de análise. Foram realizadas 12 entrevistas semiestruturadas, conduzidas com seis membros e ex-membros de cada uma das universidades. A análise de conteúdo relacionou as principais mudanças ocorridas no ambiente institucional de referência com as principais estratégias realizadas pelas universidades. Destaca-se que, apesar de existirem diferenças significativas entre as duas universidades pesquisadas, ambas buscam sua eficiência interna e para tanto, lançam mão de estratégias e táticas de respostas ao ambiente conforme cada situação considerando seus interesses. Apesar disso, o padrão de respostas estratégicas das duas universidades ao ambiente institucional permaneceu entre a aquiescência e o compromisso, indicando baixo grau de resistência às demandas institucionais, segundo o modelo analítico adotado.

Palavras-chave: Estímulos ambientais. Repostas estratégicas. Teoria Institucional. Universidades.

\begin{abstract}
Having the organizational complexity as background, in conjunction with the Oliver's (1991) tipology, which established five patterns of distinct strategic responses from the organizations to institutional processes, the present study aimed to comprehend how strategies performed by UEM - Universidade Estadual de Maringá and by PUCPR - Pontifícia Universidade Católica do Paraná were influenced by changes occurred in their institutional environments of reference between the years of 1996 and 2011. The conducted research was qualitative and descriptive and used the strategy of comparative cases study, with transversal cut and longitudinal perspective of analysis. 12 semi structured interviews were conducted with 6 members and former members of each one of the two universities. The content analysis allowed to relate the major changes in the institutional environment of reference to the major strategies used by the universities. It is possible to highlight that, although significant differences between the two universities exist, both of them seek their internal efficiency and for that, use strategies and tactics of responses to the environment in accordance to each situation considering their own interests. Nevertheless, the pattern of strategic responses of both universities to the institutional environment remained between acquiesce and compromise, indicating low degree of resistance to the institutional demands, according to the adopted analytical model.
\end{abstract}

Key words: Environmental stimuli. Strategic responses. Institutional theory. Universities. 


\section{ESTRATÉGIAS EM UNIVERSIDADES: UMA ANÁLISE COMPARATIVA SOB A PERSPECTIVA

\section{INTRODUÇÃO}

As profundas transformações ocorridas no sistema de ensino superior brasileiro ao longo dos últimos 25 anos, desde o início da década de 1990, vêm provocando mudanças ainda em curso nas organizações do setor e certo grau de instabilidade que exige, por parte das Instituições de Ensino Superior - IES, posturas estratégicas que estejam cada vez mais conectadas com o meio. As demandas, por sua vez, são nitidamente técnicas e, igualmente, institucionais, resultando em novos - e por vezes, inéditos - desafios em aspectos como a legitimidade, a qualidade do ensino oferecido, a inserção internacional, dentre outros, que tais organizações vêm procurando superar de diferentes modos.

O conjunto complexo desses aspectos requer modelos de administração universitária que associem a busca por eficiência e eficácia e o aumento da produtividade - frequentemente associada à melhoria de índices de avaliação acadêmica ou, mesmo, a avaliação da relação entre recursos utilizados e número de alunos atendidos - com aspectos de ordem social e também aqueles mais frequentemente reconhecidos como acadêmicos - a realização de pesquisas relevantes, a adequada formação de quadros profissionais, a formação científica e humanística dos alunos, dentre outros. A união destes fatores é o que permite, justamente, a distinção das IES frente a outras organizações (MEYER, 2003). Nesse sentido, a simples importação de modelos gerenciais aplicáveis a outros tipos de organização, sem que sejam resguardadas as devidas especificidades do mundo acadêmico (BLAU, 1973) acarreta o distanciamento das IES de seu objetivo fundamental, que é o benefício da sociedade que as envolve, legitima e mantém (MEYER; PASCUCCI; MANGOLIN, 2012).

O risco é que a rápida assimilação de uma abordagem mais gerencial, por parte das IES, possa levar a uma situação na qual se reduz o papel destas ao de meras organizações, o que em última instância, faz com que tais IES sejam guiadas por imperativos organizacionais de cunho puramente técnico (GUMPORT, 2000). O grande desafio das IES reside, portanto, em alcançar o equilíbrio entre um modelo de gestão que responda à lógica de mercado, para sua própria sustentabilidade financeira, e à lógica acadêmica (MEYER; MEYER, 2013).

Essa relação entre organizações e seus ambientes é um dos pontos mais estudados da teoria organizacional. Destaca-se, nesse sentido, a teoria institucional, convencionalmente entendida como uma teoria cujo foco analítico repousa na investigação da relação entre a conformidade com leis, regras culturais, referências normativas e com o quadro culturalcognitivo prevalecente, e a sobrevivência e prosperidade das organizações (DIMAGGIO; 
POWELL, 1983; JEPPERSON, 1991). Parte significativa dos estudos organizacionais baseados em teoria institucional, contudo, diverge daquela abordagem convencional, tomando como foco não a convergência de padrões ou mesmo o isomorfismo, e sim outros fenômenos, até mesmo a mudança e a divergência entre exigências ambientais e as ações organizacionais (RANSON; HINNINGS; GREENWOOD, 1980; OLIVER, 1991; SMETS; MORRIS; GREENWOOD, 2012). Tais estudos frequentemente admitem que a relação entre organizações e ambientes organizacionais deve ser entendida considerando que ambos se afetam mutuamente (GIDDENS, 2003; BERGER; LUCKMANN, 2003). Essa constitui, portanto, uma abordagem diversa daquela relação contingencial simples que admitiria apenas a determinação de padrões de ação, do ambiente para as organizações.

A perspectiva adotada neste estudo é fundamentada na relação que se estabelece entre organizações e ambientes, considerando a capacidade de agência e, consequentemente, é melhor compreendida se observada a partir da ótica da recursividade. Em outras palavras, as respostas organizacionais ao ambiente institucional não podem ser explicadas segundo uma lógica de causalidade direta e unilateral entre pressões institucionais e respostas organizacionais. Há que se considerar, no que tange à recursividade, o importante papel da agência, que permite a escolha de respostas adequadas não só ao ambiente, mas também em relação às expectativas e objetivos internos da organização (OLIVER, 1991; LAWRENCE, 1999; MACHADO-DA-SILVA; FONSECA; CRUBELLATE, 2005; CRUBELLATE et al, 2007; SMETS; MORRIS; GREENWOOD, 2012).

Baseado no exposto, o presente estudo objetivou compreender como estratégias realizadas pela Universidade Estadual de Maringá (UEM) e pela Pontifícia Universidade Católica do Paraná (PUCPR) foram influenciadas por mudanças ocorridas em seus ambientes institucionais de referência no período compreendido entre os anos de 1996 e 2011.

O item a seguir traz um panorama do sistema de ensino superior brasileiro a fim de que seja possível compreender melhor o contexto ambiental no qual as IES operam. Na sequência, o item 3 traz reflexões teóricas acerca da realização de estratégias em universidades sob a perspectiva institucional de análise. O item 4 apresenta os procedimentos metodológicos adotados para a realização da pesquisa. No item 5 é apresentado brevemente o perfil das universidades pesquisadas. O item 6 traz a análise dos dados e, por fím no item 7 são apresentadas as conclusões do estudo. 


\section{UM PANORAMA DO SISTEMA DE ENSINO SUPERIOR NO BRASIL A PARTIR DE 1990}

A crise vivida pelo Estado brasileiro durante a década de 1980 e as mudanças empreendidas no sentido de amenizá-la, desencadearam o início de uma nova configuração do governo que, apoiado em políticas neoliberais, considerando aquilo que é comumente apresentado como neoliberalismo, proporcionou significativas mudanças no país, dentre as quais se destacam aquelas no âmbito das IES. Foi a partir dos anos 1990, que o movimento de expansão e fortalecimento do setor privado impulsionou a multiplicação de IES privadas. Todo esse processo de reformulação pelo qual o Estado passou foi fortemente influenciado por intervenções internacionais (GONÇALVES, 2008).

A partir de 1996, com a chamada "Nova LDB" - Lei de Diretrizes e Bases da Educação Brasileira (LDB 9394/96), o sistema do ensino superior brasileiro passou a sofrer uma série de transformações que resultaram em sua expansão e diversificação. Com base em dados do INEP - Instituto Nacional de Estudos e Pesquisas Educacionais Anísio Teixeira (2006; 2014) verifica-se um crescimento expressivo do sistema de educação superior brasileiro no período compreendido entre 1996 e 2012, ou seja, pós-LDB. A tabela 1 mostra essa transformação em números, comparando a quantidade de IES públicas, privadas e total no país em 1996 e 2012.

Tabela 1 Sistema de ensino superior brasileiro em 1996 e 2012.

\begin{tabular}{ccccc}
\hline & \multicolumn{2}{c}{1996} & \multicolumn{2}{c}{$\mathbf{2 0 1 2}$} \\
\cline { 2 - 5 } & número & $\%$ & número & $\%$ \\
\hline TOTAL IES & 922 & $100 \%$ & 2416 & $100 \%$ \\
\hline IES PRIVADAS & 711 & $77,1 \%$ & 2112 & $87,4 \%$ \\
\hline IES PÚBLICAS & 211 & $22,9 \%$ & 304 & $12,6 \%$ \\
\hline
\end{tabular}

Fonte: Elaborado pelos autores conforme dados do INEP (2006;2014).

O sistema cresceu $162 \%$ no período, fortemente impulsionado pela multiplicação das IES privadas que aumentaram sua participação proporcional no mercado. Por outro lado, as IES públicas, que já eram minoria em 1996, passaram a ter uma participação ainda menor no mercado em termos do número de instituições.

Nesse contexto, cabe ressaltar a progressiva centralização da educação superior brasileira sob o controle do governo federal, uma vez que o sistema federal controla não somente as instituições públicas federais, mas também as IES privadas de todo o território 
nacional, enquanto que aos sistemas estaduais, cabe o controle das IES públicas estaduais e municipais (INEP, 2006).

Outro forte impacto da nova LDB no sistema de educação superior brasileiro foi o crescimento da educação tecnológica no período compreendido entre 1996 e 2012. A proporção das matrículas em cursos deste grau acadêmico, em relação ao total de matrículas no ensino superior aumentou de 3,5\% em 1996 para 13,4\% em 2012 (INEP, 2006; 2014).

As IES privadas, pelo seu foco voltado ao atendimento das demandas do mercado, objetivando oferecer uma formação mais rápida, prática e barata, investem na educação superior tecnológica. Tais instituições foram as principais responsáveis por impulsionar o crescimento na oferta de cursos desse grau acadêmico (RISTOFF; GIOLO, 2006). O mesmo acontece com a modalidade de ensino à distância - EAD. De acordo com dados do Inep (2014), em 2012, 18,8\% do total de matrículas já correspondia ao EAD, sendo que destas, $83,7 \%$ são oferecidas pelo setor privado.

Com base nos dados expostos, constata-se que a LDB de 1996 representou um marco para o sistema de educação superior brasileiro. Para Meneghel (2003, p. 223) a LDB de 1996 “implementou um modelo de Universidade adaptado às diretrizes político-econômicas do Estado neoliberal, que privilegia a satisfação de demandas do mercado por formação superior, não as demandas sociais".

Sob este mesmo ponto de vista, o momento da chamada 'democratização do ensino superior', intensificado a partir do início dos anos 2000, traz à tona a questão da validade das políticas adotadas, pois de acordo com Catani, Hey e Gilioli (2006) o governo se preocupa com o acesso dos estudantes no ensino superior e não com a sua permanência. O Programa Universidade Para Todos - Prouni, também é questionado: “[...] em que medida o Prouni é um instrumento de democratização da educação superior no Brasil ou um mero programa de estímulo à expansão das Instituições de Ensino Superior (IES) privadas?” (CATANI; HEY; GILIOLI, 2006, p. 125). O fato é que com um baixo custo orçamentário e uma natureza privatizadora, o Prouni tem forte apelo popular. Contudo, o valor correspondente aos impostos que as IES privadas deixam de pagar, poderia ser empregado no desenvolvimento e ampliação das IES públicas brasileiras (CATANI; HEY; GILIOLI, 2006; GONÇALVES, 2008). 
Silva Jr. e Sguissardi (2001) alertam para as consequências do processo de reconfiguração total do campo do ensino superior no país, que, em um sentido mais profundo, pode afetar a própria identidade da instituição universitária. Para os autores:

\begin{abstract}
a produção do conhecimento - consubstancial à ideia de universidade desde seus primórdios - tende a ser substituída pela administração de dados e informações em um processo de assessoramento ao mercado, o que impõe a sensível perda do necessário distanciamento que essa instituição deve ter em relação à sociedade, da capacidade de reflexão e crítica, característica também histórica da universidade e de qualquer outra categoria de IES (SILVA JR., SGUISSARDI, 2001, p. 269).
\end{abstract}

De fato, o número maior de diplomados no país pouco influencia uma possível diminuição da desigualdade social. Isso porque muito pode ser questionado quanto à qualidade de IES, em especial privadas fortemente orientadas por uma lógica de mercado e que não raro consideram alunos como clientes, tal como apontam Vergara e Amaral (2010). Isso reforça o paradoxo da educação apontado por Labaree (2012), segundo o qual a educação ao mesmo tempo em que existe para que a desigualdade seja reduzida, é justamente o que possibilita que uma classe se distinga e mantenha privilégios em relação às outras.

\title{
3 A REALIZAÇÃO DE ESTRATÉGIAS EM UNIVERSIDADES SOB A PERSPECTIVA INSTITUCIONAL DE ANÁLISE
}

Universidades, enquanto organizações complexas, possuem algumas especificidades que as diferenciam de outros formatos organizacionais e que implicam diretamente na sua gestão estratégica. Uma das características mais básicas de qualquer universidade é a existência simultânea, e inevitavelmente conflitante, de diversos objetivos, a começar pelo ensino, pesquisa, extensão e a própria administração geral, por assim dizer. Etzioni (1973) afirma que a ocorrência desses conflitos internos deve-se às decisões quanto à alocação de meios e recursos para cada objetivo organizacional. Baldridge (1983), também destaca a ambiguidade e a natureza difusa dos interesses existentes nas universidades, marcada pela raiz política dos grupos distintos que a compõem. Por outro lado, vai além, considerando a suscetibilidade dessas organizações ao ambiente externo, marcado pela diversidade dos interesses dos diferentes públicos que dela se beneficiam.

Cohen, March e Olsen (1972), por sua vez, cunham o termo 'anarquia organizada', para descrever a complexidade da organização acadêmica, evidenciando ao mesmo tempo a falta de controle e o surgimento de decisões autônomas pelos membros que a compõem. Weick (1976), por sua vez, considera que esse tipo de organização funcione como sistemas 
frouxamente articulados, isto é, universidades são constituídas de diversos centros de poder e ação semiautônomos que embora possuam vínculos, são independentes entre si.

Mintzberg (1995), destaca a estrutura descentralizada das organizações acadêmicas, nas quais o núcleo operacional, ou seja, os professores, são também sua parte-chave, executando parte do trabalho administrativo por meio da participação em comissões, conselhos e outros órgãos internos, assim, "não somente controlam seu próprio trabalho como também buscam o controle coletivo sobre as decisões administrativas que os afetam - por exemplo, decisões para admitir colegas, para promovê-los e para distribuir recursos" (MINTZBERG, 1995, p. 196).

Por essas razões apresentadas, pode-se dizer que exista uma maior dificuldade na ação estratégica em universidades, pois uma série de interesses e pressões diversas tanto internas quanto externas exigem decisões equilibradas e que considerem a coletividade (JARZABKOWSKI, 2005).

Embora ambas sejam organizações igualmente complexas, existem ainda distinções entre universidades públicas e privadas, principalmente no que se refere ao peso, por assim dizer, que cada uma confere aos diferentes stakeholders que constituem seu ambiente. Por exemplo, entre as privadas existe "[...] uma clara competição por alunos, professores e imagem positiva junto à comunidade, o que exige grande esforço da administração" (MEYER, 2003, p. 184), afinal, grande parte dos recursos vitais para sua sobrevivência vem das mensalidades pagas pelos alunos.

Como visto, a gestão das universidades implica amplo conhecimento acerca das especificidades deste tipo de organização de natureza complexa e cuja relação com o ambiente que a envolve, ultrapassa o âmbito competitivo mercadológico. Logo, para compreendê-las é preciso antes entender o ambiente em que elas estão inseridas, considerando a esfera institucional. Em termos conceituais podemos entender instituições como sendo "[...] compostas por elementos regulativos, normativos e cultural-cognitivos que, juntamente com atividades e recursos associados, proporcionam estabilidade e significado para a vida social" (SCOTT, 2008, p. 48, traduzido pelos autores). Esses três elementos também são chamados de "pilares" e são o que constituem e dão suporte às instituições.

Segundo Scott (2008), o pilar regulativo, envolve os processos responsáveis pelo estabelecimento de regras, fiscalização da conformidade e a aplicação de sanções, punições ou recompensas quando necessário, para o estabelecimento e manutenção da ordem. Já o pilar 
normativo enfatiza a adequação às normas e valores sociais. Enquanto os valores determinam aquilo que é desejável ou preferível, ou seja, o que deve ser feito, as normas determinam como isso deve ser feito. Dessa forma, o sistema normativo ao mesmo tempo em que define objetivos, também apresenta os meios adequados para alcança-los. Por fim, a concepção cultural - cognitiva das instituições apoia-se na construção social de um quadro comum de significados partilhados pelos diferentes atores. Nesse sentido, as ações de tais atores podem ser explicadas se analisados não somente os aspectos objetivos que envolveram determinada tomada de decisão, mas também a face subjetiva que abrange a interpretação destes aspectos objetivos por parte dos atores. É o processo cognitivo que permite a interpretação, que por sua vez, está vinculada ao quadro comum de significados (SCOTT, 2008).

Estar em conformidade com regras, leis, questões normativas e com o quadro culturalcognitivo prevalecente, confere legitimidade às organizações. Essa legitimidade implica em um forte valor simbólico na medida em que se torna aparente para o meio em que tais organizações estão inseridas. Contudo, as bases de legitimidade dos três pilares, apesar de relacionadas, são distintas e podem muitas vezes estar em conflito. Em suma, "o que é considerado como evidência de legitimidade varia de acordo com quais elementos das instituições são privilegiados bem como quais audiências ou autoridades são consultadas" (SCOTT, 2008, p. 62, traduzido pelos autores). Quanto a este aspecto, Machado-da-Silva e Gonçalves (2010, p. 224) afirmam que:

Em sociedades com forte tradição democrática e com alto nível de competição na oferta de bens e serviços, por exemplo, a tendência é que predominem os mecanismos miméticos e normativos de pressão para a estabilidade e a mudança organizacional. No caso da sociedade brasileira, a forte tradição patrimonialista associada a grandes períodos autoritários durante o seu processo de formação sociocultural tem conferido especial destaque aos mecanismos coercitivos de manutenção e de transformação social.

“[...] IES buscam, antes de tudo, legitimidade" (CRUBELLATE et al, 2007, p. 335), mas isso não implica sua conformidade a um ambiente institucional determinístico. Pelo contrário, pois a construção do mundo institucional é resultado de um processo contínuo e dialético, no qual " [...] o mundo social objetivado é reintroduzido na consciência no curso da socialização [...]” (BERGER; LUCKMANN, 2003, p. 87). Complementarmente, Machadoda-Silva, Fonseca e Crubellate (2005, p. 13) afirmam que "[...] estrutura e agência são conectadas recursivamente, baseadas na interpretação, como um mecanismo básico cognitivo, que permite a reciprocidade entre estes elementos [...]”. 
A perspectiva institucional de análise das organizações e o pensamento estratégico são muitas vezes tratados na literatura como abordagens incomunicáveis entre si que partem de pressupostos completamente distintos. Tal visão reducionista da institucionalização e da agência estratégica é superada quando se tomam essas duas abordagens, em conjunto, buscando superar as limitações inerentes em cada uma e ampliando a análise para além da dicotomia entre determinismo ambiental e voluntarismo (CRUBELLATE; GRAVE; MENDES, 2004).

Essa concepção de indivíduos ou organizações agindo “[...] em discordância com os arranjos institucionais estabelecidos e que podem eventualmente muda-los" é denominado empreendedorismo institucional (LECA; BATTILANA; BOXENBAUM, 2006, p. 5). Muitos são os autores que contribuíram com pesquisas compartilhando esse entendimento, como: Oliver (1991); Lawrence (1999); Machado-da-Silva, Fonseca e Crubellate (2005); Crubellate et al (2007); Scott (2008) e Tolbert, David e Sine (2011).

O trabalho de Oliver (1991), por meio da convergência entre teoria institucional e a teoria da dependência de recursos, buscou configurar padrões de respostas estratégicas a processos institucionais. Dessa forma, a autora desenvolveu uma tipologia que permite identificar cinco categorias de respostas estratégicas aos processos institucionais, conforme mostrado no quadro 1. O posicionamento dos atores frente às pressões institucionais desencadeiam estratégias de ação distintas, desde aquiescência até manipulação do próprio ambiente institucional. Cada estratégia pode adotar ainda táticas diferentes.

\begin{tabular}{|c|c|c|}
\hline ESTRATÉGIAS & TÁTICAS & EXEMPLOS \\
\hline \multirow{3}{*}{ AQUIESCÊNCIA } & Hábito & Seguir normas invisíveis, dadas como certas \\
\cline { 2 - 3 } & Imitar & Imitar modelos institucionais \\
\cline { 2 - 3 } & Aceder & Obedecer às regras e aceitar as normas \\
\hline \multirow{3}{*}{ COMPROMISSO } & Equilibrar & Equilibrar as expectativas de públicos múltiplos \\
\cline { 2 - 3 } & Pacificar & Aplacar e acomodar elementos institucionais \\
\cline { 2 - 3 } & Barganhar & Negociar com grupos de interesse institucionais \\
\hline \multirow{3}{*}{ ESQUIVANÇA } & Ocultar & Disfarçar a não conformidade \\
\cline { 2 - 3 } & Amortecer & Afrouxar as ligações institucionais \\
\cline { 2 - 3 } & Escapar & Mudar objetivos, atividades ou domínios \\
\hline \multirow{3}{*}{ DESAFIO } & Rejeitar & Desconsiderar normas e valores explícitos \\
\cline { 2 - 3 } & Provocar & Contestar regras e exigências \\
\cline { 2 - 3 } & Atacar & Violar as fontes de pressão institucional \\
\hline \multirow{3}{*}{ MANIPULAÇÃO } & Cooptar & Importar pessoas influentes \\
\cline { 2 - 3 } & Influenciar & Moldar valores e critérios \\
\cline { 2 - 3 } & Controlar & Dominar públicos e processos institucionais \\
\hline
\end{tabular}

Quadro 1 Respostas Estratégicas a Processos Institucionais.

Fonte: Oliver (1991, p. 152, traduzido por MACHADO-DA-SILVA, 2003, p. 68). 
Resumidamente, as respostas organizacionais ao ambiente institucional dependem de uma série de fatores que fazem com que elas não sejam padronizadas. Há de se considerar a capacidade interna organizacional, os motivos que originaram as pressões e quem e como as exerceu. As organizações situam-se, portanto, em algum lugar entre a busca pela legitimidade institucional e a busca pela eficiência organizacional (OLIVER, 1991).

Como visto, a realização de estratégias pode ser analisada a partir de um enfoque institucional, superando o determinismo ambiental e o voluntarismo estratégico. Isso permite a adoção de uma visão mais ampla acerca das possibilidades de respostas estratégicas ao ambiente.

\section{PROCEDIMENTOS METODOLÓGICOS}

O presente estudo foi conduzido a partir de algumas premissas a respeito da relação entre organizações e seus ambientes: a) a construção do mundo institucional é resultado de um processo contínuo e recursivo, no qual o mundo social e a coletividade são ao mesmo tempo produto e produtores um do outro; b) mudanças no ambiente institucional provocam mudanças nas organizações, e; c) universidades buscam legitimar-se ao mesmo tempo em que buscam maior eficiência organizacional. De igual modo, foram adotadas algumas premissas a respeito de estratégia em organizações: a) estratégias são como ferramentas utilizadas pelas organizações para enfrentarem as mudanças que ocorrem no ambiente; b) a formação de estratégias incorpora elementos ambientais, cognitivos, culturais e sistêmicos, e; c) estratégias realizadas englobam estratégias deliberadas e emergentes.

Da relação entre tais premissas, o seguinte questionamento norteou o presente estudo: Como estratégias realizadas pela UEM (Universidade Estadual de Maringá) e pela PUCPR (Pontifícia Universidade Católica do Paraná) foram influenciadas por mudanças ocorridas em seus ambientes institucionais de referência entre os anos de 1996 e 2011 ?

Tendo em vista o objetivo geral do presente estudo, no que concerne às estratégias de pesquisa, optou-se pelo estudo de caso haja vista a diversidade de técnicas de coleta de dados (GOODE; HATT, 1979; BRUYNE; HERMAN; SCHOUTHEETE, 1977). Tal escolha também se pautou no que afirma YIN (2005), isto é, que a utilização de um estudo de caso costuma ser uma estratégia especialmente útil quando o pesquisador parte de perguntas do tipo 'como' e 'por que'. 
A escolha dos entrevistados para este estudo deu-se tendo em vista que nas universidades, enquanto 'burocracias profissionais' (MINTZBERG, 1995), os professores executam parte do trabalho administrativo, participando de comissões, conselhos e outros cargos administrativos. Por essa razão, foram entrevistados professores das duas universidades que, entre os anos de 1996 e 2011, tiveram participação no processo decisório dessas instituições como membros de conselhos superiores, reitores e pró-reitores. A exigência de alguns cargos, todavia, fez com que alguns dos entrevistados não exercessem a docência pelo período de seus mandatos. No caso da PUCPR, constatada a importância da mantenedora no fenômeno estudado, um ex-membro dessa instituição foi entrevistado, dada sua participação no processo estratégico corporativo do Instituto Marista e, posteriormente, sua participação no processo estratégico da PUCPR.

Optou-se por pesquisar a partir do ano de 1996, pois a chamada 'Nova LDB', do mesmo ano, foi um verdadeiro marco para as IES brasileiras. O intervalo de 15 anos entre 1996 e 2011 permitiu identificar importantes traços acerca da relação entre as universidades e o ambiente institucional.

A coleta de dados foi realizada em duas etapas. A primeira etapa teve como objetivo traçar um panorama geral, uma espécie de mapa do ambiente institucional de referência das duas IES pesquisadas, a fim de reunir tantos elementos quanto possível por meio da análise de dados secundários, estes obtidos através da consulta a documentos. Nessa etapa foram pesquisados documentos externos às IES, tais como regulamentações pertinentes que pudessem ter exercido influência nas estratégias realizadas pela UEM e pela PUCPR, dados provenientes de fontes como o INEP, que demonstrassem a conjuntura do sistema de ensino superior brasileiro no período de interesse da pesquisa, bem como artigos científicos, dissertações e teses, cujos autores tivessem, de alguma forma, estudado o sistema de ensino superior brasileiro.

Uma vez tendo constituído este primeiro mapa do ambiente institucional de referência das duas IES pesquisadas, teve início a segunda etapa da coleta de dados, caracterizada pela realização de entrevistas semiestruturadas. Foram realizadas 12 entrevistas, 6 com professores e ex-professores da UEM, 5 com professores da PUCPR e 1 entrevista com um exprofissional da PUCPR. Desses entrevistados, 6 tinham entre 20 e 39 anos de trabalho na IES correspondente, 5 tinham entre 10 e 19 anos de trabalho e 1 tinha menos de 5 anos de trabalho na IES. O critério utilizado para chegar ao número de 12 entrevistados foi a repetição de 
informações, isto é, verificou-se que já não haviam elementos novos nas falas dos entrevistados. $\mathrm{O}$ objetivo desta etapa foi identificar as principais estratégias realizadas pelas duas IES pesquisadas, a partir das falas dos entrevistados, bem como refinar o desenho do primeiro mapa do ambiente institucional de referência das mesmas, acrescentando ou excluindo elementos, também de acordo com o que foi apontado nas entrevistas.

A análise do material obtido com a pesquisa deu-se por meio da análise de conteúdo conforme Bardin (1977), na qual a interpretação dos dados sucedeu a codificação e categorização prévia dos mesmos. Foram utilizados dois softwares com o intuito de facilitar o preparo e análise dos dados. O primeiro foi o Express Scribe, unicamente para a transcrição das entrevistas. Cumprida esta etapa, todas as entrevistas já transcritas foram transpostas para o Software Atlas TI 7, para facilitar a análise de conteúdo.

\section{PERFIL DAS UNIVERSIDADES PESQUISADAS}

A UEM foi criada em 1970. Em 2011, a universidade oferecia 61 cursos de graduação presencial, 7 cursos de graduação a distância, 55 cursos de pós-graduação stricto sensu (sendo 34 mestrados e 21 doutorados) e 68 cursos de pós-graduação lato-sensu. Em termos de estrutura, eram 7 campi, 7 centros de ensino e 47 departamentos. Em relação à quantidade de alunos matriculados, tinha-se o expressivo número de 26.431 no total (UEM..., 2012).

A PUCPR foi criada em 1959, sendo a primeira universidade privada do Estado do Paraná. Trata-se de uma universidade privada, comunitária e confessional. Sua mantenedora, a APC (Associação Paranaense de Cultura) é uma das organizações do Grupo Marista e foi criada em 1950, com o objetivo de manter a PUCPR. A APC é uma associação civil de direito privado, filantrópica e com fins educacionais. Em 2011, academicamente, a universidade era organizada por nove escolas que, juntas, totalizavam 64 cursos. A universidade estava presente em 5 campi universitários e contava com mais de 30 mil alunos. Na pós-graduação lato-sensu possuía 200 cursos e no stricto sensu possuía 14 mestrados e 10 doutorados. Em termos de pesquisa, a instituição possuía destaque sendo responsável por $20 \%$ da publicação científica do Estado do Paraná (GRUPO MARISTA, 2013). 


\section{INTERPRETANDO A RELAÇÃO ENTRE O AMBIENTE INSTITUCIONAL E ESTRATÉGIAS DAS UNIVERSIDADES PESQUISADAS}

Os dados concernentes às duas universidades, permitiram observar que ao longo do período analisado, o padrão de suas respostas estratégicas ao ambiente institucional permaneceu entre a aquiescência e o compromisso.

A aquiescência, para Oliver (1991, p. 153) “[...] depende do desejo consciente da organização de agir em conformidade, do seu grau de conhecimento dos processos institucionais e sua expectativa de que a conformidade estará servindo aos interesses organizacionais".

Como táticas empregadas dentro da estratégia da aquiescência, tem-se que tanto a UEM quanto a PUCPR agiram, em diferentes circunstâncias, motivadas por: a) hábitos, seguindo normas invisíveis dadas como certas; b) imitação de modelos institucionais; e c) acedência, obedecendo às regras e aceitando normas.

A tática de agir conforme hábitos, de acordo com Oliver (1991), representa a aderência a regras ou valores tidos como certos, sem que se reflita sobre o porquê dessa decisão. Isso acontece especialmente quando normas institucionais adquirem o status de um fato social. Dessa forma, as organizações repetem certos atos e práticas sem maiores reflexões estratégicas de tal comportamento.

No caso da UEM, constatou-se o hábito nas seguintes situações: a) o grande aumento do número de cursos de graduação ao longo dos últimos anos. Grande parte dos entrevistados enfatizou o crescimento, mas o justificam como sendo um fim em si mesmo. Um único entrevistado posicionou-se de modo crítico a esse crescimento quantitativo dos cursos. Os demais têm enraizada em si a crença de que quanto maior a universidade, melhor ela é, sem que isso demande qualquer tipo de justificativa adicional; b) a manutenção da mesma estrutura administrativa com muitas instâncias, isto é, com centros e departamentos, desde sua fundação no início da década de 1970. Apesar da existência de diversos exemplos de IES que são referência para a própria UEM e que possuem outro modelo de estrutura com mais autonomia para as áreas, não se busca essa alteração na universidade e, c) o prevalecimento de uma postura contrária ao estabelecimento de parcerias com a iniciativa privada objetivando a obtenção de recursos para a universidade e, ao mesmo tempo, o repasse de inovação para essas empresas. Cabe ressaltar que todos os entrevistados repudiam essa postura contrária às 
parcerias, mas afirmam que apesar de ela estar diminuindo na instituição ao longo dos últimos anos, ela ainda existe e é forte.

Por outro lado, no caso da PUCPR, não se observou a tática do hábito no seu padrão de respostas ao ambiente institucional.

A tática da imitação, de acordo com Oliver (1991), se relaciona com o conceito de isomorfismo mimético. Ela ocorre tanto por meio de processos conscientes quanto inconscientes de mimetismo de modelos institucionais. A imitação de outras organizações bem-sucedidas do setor é um exemplo deste comportamento.

Devido à força do isomorfismo no âmbito das IES, tanto a UEM quanto a PUCPR apropriaram-se de exemplos de gestão e modelos acadêmicos provenientes de outras IES consideradas de referência. A PUCPR, em especial, tem feito isso de maneira bem clara, tendo em vista sua estratégia norteadora de internacionalização, que tomou forma a partir de 2010.

Ainda dentro da estratégia da aquiescência, a tática da acedência reflete a obediência consciente ou a incorporação de requisitos institucionais, regras e normas. É importante ressaltar que nessa tática a organização exerce uma escolha estratégica ao optar por obedecer às demandas institucionais, visando beneficiar-se com isso aumentando sua legitimidade e suporte contextual.

No caso da UEM, constatou-se a tática da acedência nessas situações: a) a implementação das cotas sociais - estratégia em concordância com as políticas afirmativas nacionais; b) a implementação do ensino a distância - estratégia também em consonância com as políticas de ampliação do acesso ao ensino superior; c) a criação de campi universitários em outras cidades, também em concordância com tais políticas.

No caso da PUCPR, verifica-se a tática da acedência também na criação de novos campi universitários em outras cidades do Estado, entre o final da década de 90 e os primeiros anos da década seguinte.

De acordo com Oliver (1991) as organizações têm muitas vezes que enfrentar dilemas entre demandas institucionais conflitantes ou mesmo entre interesses organizacionais e expectativas institucionais. Nessas situações, elas podem adotar táticas de equilíbrio, pacificação ou barganha, que constituem o padrão de estratégia denominado compromisso.

A estratégia do compromisso foi utilizada pelas duas universidades. Observou-se que ambas valeram-se das três táticas da estratégia do compromisso: a) equilíbrio entre as 
expectativas de públicos múltiplos; b) pacificação, aplacando e acomodando elementos institucionais; e, c) barganha, negociando com grupos de interesse institucionais.

A tática do equilíbrio, segundo Oliver (1991) trata da acomodação das demandas de múltiplos públicos. As organizações, nesse caso, buscam o equilíbrio entre os múltiplos stakeholders e os interesses internos.

No caso da UEM, constata-se a tática do equilíbrio na criação do Programa de Avaliação Seriada - PAS como uma alternativa ao vestibular. A universidade, por um lado, precisava de um processo seletivo eficiente para receber bons alunos para seus cursos de graduação e, por outro lado, a sociedade questionava se o vestibular era, de fato, a melhor forma de avaliar os candidatos aos cursos da UEM. A criação do PAS como uma forma alternativa de ingresso na universidade acomodou ao mesmo tempo demandas internas e externas à universidade.

No caso da PUCPR, verificou-se a tática do equilíbrio nessas situações: a) a criação da Agência PUC de Ciência, Tecnologia e Inovação em 2008 pela PUCPR e pela sua mantenedora, a APC, com o objetivo de estreitar os laços entre o setor empresarial e a universidade, via produção e transferência de conhecimento científico ligado especialmente à tecnologia. O aumento de parcerias com empresas privadas tendo como pano de fundo a pesquisa e a inovação beneficia, por um lado, a instituição trazendo recursos e melhorando a qualidade do ensino e, por outro lado, satisfaz uma demanda da inciativa privada que busca o desenvolvimento de novas tecnologias em parceria com a universidade; b) a relação entre a PUCPR e sua mantenedora, a APC, é marcada pela negociação e nunca pela imposição e, c) a escolha das áreas nas quais a instituição irá investir está em consonância com as áreas que são identificadas como prioridade pelo governo e por outros organismos, tais como a Organização para a Cooperação e Desenvolvimento Econômico (OCDE).

Já a tática da pacificação, segundo Oliver (1991), significa que a organização apresenta um baixo grau de resistência a pressões institucionais, mas por outro lado, significa também que ela utiliza sua energia para apaziguar ou aplacar a fonte institucional que a pressiona.

No caso da UEM, constatou-se a tática da pacificação na ocasião da criação do Conselho de Integração Universidade-Comunidade em 2008 com o objetivo de trazer a comunidade - fonte de grande parte das pressões institucionais exercidas - para dentro da universidade no âmbito da gestão, para que essa relação fosse de maior entendimento. 
No caso da PUCPR, verificou-se a tática da pacificação na transmissão do ideário católico e Marista para alunos via a disciplina obrigatória denominada "Projeto Comunitário", que é também uma forma de influenciar a sociedade conforme certas crenças e valores.

Por fim, a tática da barganha, conforme Oliver (1991), é mais ativa do que a tática da pacificação, pois envolve negociações estratégicas diretas com grupos de interesse institucionais, visando uma melhor adequação de demandas e expectativas externas com os interesses organizacionais. Nessa situação, a organização busca seus próprios interesses de forma mais ativa.

No caso da UEM, constatou-se a tática da barganha no estabelecimento de alianças com a comunidade e o Estado com o intuito de conseguir maior suporte para a abertura de cursos.

Na PUCPR, verificou-se a tática da barganha nessas situações: a) a criação da área denominada Relações Institucionais e sua atuação direta junto aos órgãos regulativos que, de alguma maneira, impactam a universidade; b) a participação em associações de universidades católicas e também de universidades privadas para ganhar mais poder de articulação junto ao governo.

Com base no exposto até aqui, é possível concluir que as universidades pesquisadas não agiram buscando somente a legitimidade contextual, isto é, elas buscaram sua eficiência interna e para tanto, lançaram mão de estratégias e táticas de respostas ao ambiente conforme cada situação e considerando seus interesses. De fato, as universidades respondem ao ambiente institucional dentro de possibilidades de respostas que vão muito além da simples conformidade. Suas estratégias, sejam elas emergentes ou deliberadas, refletem um comportamento que une, em diferentes proporções, conformidade e resistência às pressões institucionais. Apesar disso, o grau de resistência às demandas e expectativas institucionais dadas é consideravelmente baixo. Uma razão para isso é a força dos elementos regulativos presentes no ambiente institucional das universidades, pois como mencionado, em sociedades como a brasileira, destacam-se os mecanismos coercitivos de manutenção e transformação social (MACHADO-DA-SILVA; GONÇALVES, 2010). Assim, é comum existirem poucos espaços para a ação.

Todavia, os entrevistados da PUCPR demonstraram maior inquietação em relação a essas pressões institucionais e, por esse motivo, se organizou de tal forma a permitir a constante negociação com grupos de interesse institucionais, inclusive influenciando órgãos 
regulativos. Sua sobrevivência e desempenho organizacional, enquanto instituição privada, dependem dessa gestão mais ativa em termos institucionais, isto é, dependem do chamado empreendedorismo institucional (LECA; BATTILANA; BOXENBAUM, 2006). Esse posicionamento não decorre automaticamente do fato de ser uma IES privada e sim do fato de ter um planejamento estratégico que, para ser realizado, precisa de condições não só internas, mas sobretudo externas.

Os entrevistados da UEM, por outro lado, demonstraram que a instituição teve uma postura mais reativa no que concerne às pressões institucionais do ambiente regulativo. É importante mencionar que, sendo uma universidade pública, sua relação com o governo é mais próxima e de maior dependência, se comparada à PUCPR. Mas essa proximidade, ao contrário do que se poderia pensar, não contribuiu para uma maior influência da universidade nos processos regulativos. Pelo contrário, possivelmente o distanciamento da fonte de pressões regulativas, conferiria à universidade maior poder de ação sobre essa fonte, visto que os limites do governo e da própria universidade seriam melhor delineados.

Apesar da existência do Plano de Desenvolvimento Institucional - PDI na UEM, não foi possível identificar por meio das entrevistas, uma grande diretriz norteadora que reunisse todos os esforços de todas as áreas para o alcance de um objetivo claro e comum. Não foi identificado, como no caso da PUCPR, um direcionamento claro e amplamente partilhado pelos membros de 'onde a instituição quer chegar' ou 'que tipo de universidade a UEM quer ser e como isso será realizado'.

Essa constatação vem ao encontro do que afirmam vários autores acerca da complexidade organizacional. A UEM possui de maneira muito evidente os atributos definidos por Cohen, March e Olsen (1972) para o que eles chamam de "anarquia organizada"; ou ainda as características dos "sistemas frouxamente articulados" (WEICK, 1976) e; as especificidades das "burocracias profissionais" (MINTZBERG, 1995). Ela também apresenta as características destacadas por Baldridge (1983) isto é, a ambiguidade e a natureza difusa dos interesses existentes, suas raízes políticas influenciadas pelos diferentes grupos que nela atuam, a diversidade de interesses da clientela, a complexa tecnologia envolvida nos processos e a suscetibilidade ao ambiente externo.

A complexidade organizacional também é evidente na PUCPR, contudo, percebe-se que naquela IES, ainda que o processo de elaboração de estratégias contasse com a colaboração das áreas, existe uma equipe dedicada a coordenar sua elaboração. Isso fez com 
que houvesse maior consonância entre a grande estratégia norteadora da instituição e as demais estratégias. No entanto, nem sempre foi assim. As entrevistas revelaram que houve insucesso no passado quando tentou-se elaborar um planejamento estratégico deixando todas as áreas à vontade para fazerem suas propostas. O planejamento, naquela ocasião, não conseguiu ser operacionalizado.

Por fim, foi perceptível o dilema que essas universidades enfrentam pelo fato de serem organizações complexas. Por um lado, seu sucesso depende de conseguirem se posicionar estrategicamente frente aos desafios constantes do ambiente institucional em que estão inseridas. Por outro lado, internamente, precisam concatenar os múltiplos interesses e necessidades dos diferentes grupos que nelas atuam, com vistas a responder estrategicamente ao ambiente, sem que isso fira a autonomia do corpo docente, isto é, o caminho deve estar mais voltado à negociação, por mais difícil e desgastante que seja, do que à imposição.

\section{CONCLUSÕES}

As análises que antecederam este último item de conclusão vão ao encontro da literatura pesquisada no que diz respeito às possibilidades de respostas estratégicas às pressões ambientais. As universidades não buscam somente legitimar-se no contexto em que estão inseridas; elas buscam sua eficiência interna e dessa forma, respondem estrategicamente ao meio, indo além da simples conformidade. Ainda assim, o ambiente altamente regulado deixa pouco espaço para agência. Tendo isso em vista, de acordo com os dados aos quais os pesquisadores tiveram acesso, a PUCPR organizou-se de maneira a exercer influência sobre o ambiente regulativo, e o faz sistematicamente por meio de uma área denominada relações institucionais, contando em muitos casos com o trabalho conjunto de associações que compartilham os mesmos interesses que a universidade enquanto IES privada e católica.

Não é possível relacionar este comportamento da PUCPR no sentido de agir sobre as fontes de pressão institucional, com o fato de ser uma IES privada. Acredita-se que o determinante para este posicionamento é o seu planejamento estratégico claro e bem definido, que para ser alcançado, demanda articulações no nível institucional.

A relação de proximidade e dependência da UEM para com o poder público parece constituir uma das razões para que ela não exerça plenamente seu poder de agência no âmbito regulativo. Essa proximidade impede, de certa forma, que se estabeleçam limites mais delineados de qual vem a ser o possível espaço de atuação da universidade. Outra razão para 
essa postura mais reativa em relação ao ambiente regulativo é que, apesar da existência do PDI na UEM, ele não representa uma macro estratégia norteadora para os entrevistados.

A influência de aspectos da complexidade organizacional sobre o "fazer estratégia" foi, portanto, especialmente percebida no caso da UEM. Ainda que a PUCPR também apresente as características de uma organização complexa, verificou-se que essa complexidade é gerida de maneira a possibilitar o estabelecimento de estratégias amplamente difundidas e buscadas por todas as áreas, mesmo que com intensidades diferentes. Todavia, este é um posicionamento mais recente da PUCPR, pois houve insucesso em anos anteriores, quando da implementação de um planejamento estratégico que tentava abarcar toda a diversidade e a multiplicidade de interesses das diferentes áreas.

Constatou-se também que este é um ambiente onde a presença do isomorfismo é muito forte. Ambas as instituições se valem de outros exemplos tanto no âmbito da gestão, quanto no âmbito acadêmico. A qualificação docente, por meio do envio e acolhimento de professores para cursarem programas stricto sensu, constitui uma das principais formas de transmissão de conhecimento e práticas entre diferentes universidades.

Como sugestão para pesquisas futuras, outros estudos podem ampliar a diversidade de casos comparando também universidades federais e universidades privadas com fins lucrativos. Outra possibilidade, é pesquisar à luz da teoria institucional como se dá o processo da criação de legislações pertinentes ao ensino superior brasileiro, considerando quem são os agentes envolvidos nesse processo e como se relacionam.

\section{REFERÊNCIAS}

BALDRIDGE, J.V. Strategic planning in higher education: does the emperor have any clothes? In: BALDRIDGE, J.V.; DEAL, T. The dynamics of organizational change in education. Berkeley: Mc-Cutchan, 1983. p. 167-185.

BARDIN, Laurence. Análise de conteúdo. Lisboa: Edições 70, 1977.

BERGER, P.; LUCKMANN, T. A Construção Social de Realidade: Tratado de Sociologia do Conhecimento. Tradução Floriano de Souza Fernandes. 23. ed. Petrópolis: Vozes, 2003.

BLAU, P. The Organization of Academic Work. New York: John Wiley \& Sons, 1973.

BRUYNE, P. de; HERMAN, J.; SCHOUTHEETE, M. de. Dinâmica da pesquisa em ciências sociais: os pólos da prática metodológica. Tradução de Ruth Joffily. Rio de Janeiro: F. Alves, 1977. 
CATANI, A. M.; HEY, A. P.; GILIOLI, R. S. P. PROUNI: democratização do acesso àsInstituições de Ensino Superior? Educar, n. 28, p. 125-140. Curitiba: Editora UFPR, 2006.

COHEN, M.; MARCH, J. G.; OLSEN, J. P. A Garbage Can Model of Organizational Choice. Administrative Science Quarterly, v. 17, n. 1, p. 1-25, Mar. 1972.

CRUBELlATE, J. M.; GRAVE, P. S.; MENDES, A. A. A questão institucional e suas implicações para o pensamento estratégico. RAC- Revista de Administração Contemporânea, v. 8, p. 37-60, ed. especial, 2004.

CRUBELlATE, J. M.; SOUZA, B. E.; MORIBE, G.; TEIXEIRA, M. G. Panorama Institucional-Legal, Avaliação e Controle de Qualidade de Ensino em uma Universidade Pública. Gestão.Org - Revista Eletrônica de Gestão Organizacional, v. 5, n. 3, p. 330-354, set./dez. 2007.

DIMAGGIO, Paul J.; POWELL, Walter W. The Iron Cage Revisited: Institutional Isomorphism and Collective Rationality in Organizational Fields. American Sociological Review, v. 48, n. 2, p. 147-160, 1983.

ETZIONI, A. Organizações Modernas. Tradução de Miriam L. Moreira Leite. 3 ed. São Paulo: Pioneira, 1973.

GIDDENS, A. A constituição da sociedade. Tradução de Álvaro Cabral. 2 ed. São Paulo: Martins Fontes, 2003.

GONÇALVES , S. A. Estado e expansão do ensino superior privado no Brasil: uma análise institucional dos anos de 1990. Educar, n. 31, p. 91-111. Curitiba: Editora UFPR, 2008.

GOODE, W. J.; HATT, P. K. Métodos em pesquisa social. Tradução de Carolina Martuscelli Bori. 7 ed. São Paulo: Ed. Nacional, 1979.

GRUPO MARISTA. Ensino Superior. Disponível em:

http://www.grupomarista.org.br/educacao-ensino-superior/D12/. Acesso em: 22 fev. 2013.

GUMPORT, P. J. Academic restructuring: organizational change and institutional imperatives. Higher Education, v. 39, n. 1, p. 67-91, 2000.

INEP - Instituto Nacional de Estudos e Pesquisas Educacionais Anísio Teixeira. Censo da educação superior 2012: resumo técnico. Brasília : Inep, 2014. Disponível em:

http://download.inep.gov.br/download/superior/censo/2012/resumo tecnico_censo_educacao superior_2012.pdf. Acesso em 05 jan. 2015.

Educação Superior Brasileira 1991-2004 - Paraná. Brasília: Inep, 2006.

Disponível em: http://www.publicacoes.inep.gov.br/portal/download/648 . Acesso em 05 Jan. 2015.

JARZABKOWSKI, P. Strategy as Practice: an activity-based approach. London: Sage Publications, 2005. 
JEPPERSON, R. L.. Institutions, Institutional Effects and Institutionalism. In: POWELL, W. W.; DIMAGGIO, P. J. (orgs.). The New Institutionalism In Organizational Analysis. Chicago: University of Chicago Press. 1991, p. 143-163.

LABAREE, D. F. School syndrome: Understanding the USA's magical belief that schooling can somehow improve society, promote access, and preserve advantage. Journal of Curriculum Studies, v. 44, n. 2, p. 143-163, 2012. Disponível em: https://web.stanford.edu/ dlabaree/publication2011/School_Syndrome.pdf. Acesso em: 20 dez. 2014.

LAWRENCE, T. B. Institutional Strategy. Journal of Management, v. 25, n. 2, p. 161-188, 1999.

LECA, B.; BATTILANA, J.; BOXENBAUM, E. Taking Stock on Institutional Entrepreneurship: what do we know? Where do we go? In: Academy of Management Meetings, 2006, p. 1-43.

MACHADO-DA-SILVA, C. L.; FONSECA, V. S. DA; CRUBELLATE, J. M.. Unlocking the institutionalization process: insights for an institutionalizing approach. BAR- Brazilian Administration Review, v. 2, n. 1, p. 01-20, 2005.

MACHADO-DA-SILVA, C. L.; GONÇALVES, S. A. Nota Técnica: A Teoria Institucional. In: CLEGG, S.; HARDY, C.; NORD, W. (Orgs.). Handbook de estudos organizacionais. v.1. São Paulo: Atlas, 2010. p. 218-225.

MENEGHEL, S. M. . A Função da Universidade na Sociedade - elementos para repensar a organização universitária brasileira. In: ZAINKO, M. A S.; GISI, M. L.. (Orgs.). Políticas e Gestão da Educação Superior. Curitiba: Champagnat, 2003, p. 223-247.

MEYER, B.; MEYER, V. "Managerialism” na Gestão Universitária: Uma Análise de Suas Manifestações em uma Instituição Empresarial. Revista GUAL - Gestão Universitária na América Latina, v.6, n. 3, p. 01-20, set. 2013.

MEYER, V. Novo Contexto e as Habilidades do Administrador Universitário. In: MEYER, V. MURPHY, J, P. (Orgs.). Dinossauros, Gazelas e Tigres. Novas Abordagens da Administração Universitária. Um Diálogo Brasil e EUA. $2^{\mathrm{a}}$ ed. ampliada. Florianópolis: Insular, 2003, p. 173-192.

MEYER, V.; PASCUCCI, L.; MANGOLIN, L. Gestão estratégica: um exame de práticas em universidades privadas. RAP - Revista de Administração Pública, Rio de Janeiro, v. 46, n. 1, p. 49-70, jan./fev. 2012.

MINTZBERG, H. Criando organizações eficazes: estruturas em cinco configurações. Tradução de Ciro Bernardes. São Paulo: Atlas, 1995.

OLIVER, C. Strategic responses to institutional processes. Academy of Management Review, v. 16, n.1, p. 145-179, 1991. 
RANSON, S.; HININGS, C. R.; GREENWOOD, R. The Structuring of Organizational Structures. Administrative Science Quarterly, v. 25,n. 1, p. 1-17, 1980.

RISTOFF,D.; GIOLO, J. Introdução: A Educação Superior no Brasil - Panorama Geral. In: INEP - Instituto Nacional de Estudos e Pesquisas Educacionais Anísio Teixeira. Educação Superior Brasileira 1991-2004 : Paraná. Brasília: Inep, 2006, p. 13-20.

SCOTT, W. R. Institutions and organizations: ideas and interests. 3 ed. Los Angeles: Sage, 2008 .

SILVA JR. J. dos R.; SGUISSARDI, V. Novas faces da educação superior no Brasil: reforma do Estado e mudança na produção. 2 ed. rev. São Paulo: Cortez, 2001.

SMETS, M.; MORRIS, T.; GREENWOOD, R. From Practice To Field: a multi-level model of practice-driven institutional change. Academy of Management Journal, v. 55, n.4, p. 877-904, 2012.

TOLBERT, P. S.; DAVID, R. J.; SINE, W. D. Studying Choice and Change: The Intersection of Institutional Theory and Entrepreneurship Research. Organization Science, v. 22, n. 5, p. 1332-1344, 2011.

UEM - UNIVERSIDADE ESTADUAL DE MARINGÁ. Assessoria de Planejamento. Coordenadoria de Planos e Informações. Base de dados 2012: ano base 2011. Maringá: UEM-ASP, 2012. Disponível em:

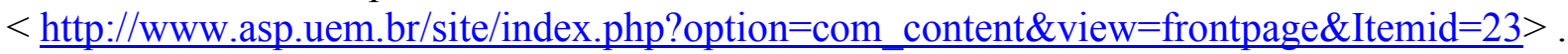
Acesso em: 08 maio 2013.

VERGARA, S. C.; AMARAL, M. M. do. Reflexões Sobre o Conceito 'Aluno-Cliente' de Instituições de Ensino Superior Brasileiras. In: : ENANPAD - ENCONTRO NACIONAL DOS PROGRAMAS DE PÓS-GRADUAÇÃO EM ADMINISTRAÇÃO, 2010, Rio de Janeiro. Anais... Rio de Janeiro: ANPAD, 2010.

WEICK, K. E. Educational Organizations as loosely coupled systems. Administrative Science Quarterly, 1976, n.21, p.1-19.

YIN, R. K. Estudo de caso: planejamento e métodos. 3 ed. Tradução de Daniel Grassi. Porto Alegre: Bookman, 2005. 